\title{
Las críticas de TripAdvisor como herramienta didáctica en el aula de español del turismo
}

\author{
ISABEL GARCÍA MARTÍNEZ \\ Universidad de Cantabria \\ garciamis@unican.es
}

\begin{abstract}
Resumen: Este artículo tiene como objetivo señalar la importancia de incluir y aprovechar en el aula de español con fines profesionales (Efp) los nuevos materiales del ámbito del turismo que han surgido en los últimos años. El trabajo parte del análisis pragmalingüístico de un corpus de elaboración propia de comentarios negativos de TripAdvisor. Después se señalan sus posibilidades didácticas para su implementación en el aula de español del turismo.
\end{abstract}

Palabras clave: TripAdvisor, turismo, fines específicos, crítica.

\section{TripAdvisor reviews as a teaching tool in the Tourism Spanish Classroom}

Abstract: The purpose of this article is to point out the importance of including and taking advantage of the new materials in the field of tourism that have emerged in recent years in the Spanish classroom for professional purposes (Efp). The work starts from the pragmalinguistic analysis of a corpus of own elaboration of negative reviews from TripAdvisor. Then its didactic possibilities for its implementation in the Spanish classroom of tourism are indicated.

Key words: TripAdvisor, tourism, specific purposes, review.

\section{Introducción: Aproximación a la lengua del turismo}

El estudiante de una lengua de especialidad, en este caso, del turismo, necesita adquirir la lengua para comunicarse en su entorno profesional. La llegada de Internet, las nuevas tecnologías y la Web 2.0 han supuesto una revolución en muchos ámbitos, incluidos los géneros discursivos con la aparición de los cibergéneros. La plataforma TripAdvisor es una de las más usadas en el mundo del turismo, por tanto, puede ser una de las herramientas para incorporar y utilizar en el aula, pues es una herramienta utilizada en el ámbito laboral turístico. Por ello, los objetivos propuestos en este trabajo son señalar la importancia de incluir y aprovechar en el aula de Efp los nuevos materiales del ámbito del turismo que han surgido en los últimos años, proponer la plataforma TripAdvisor como una herramienta de enseñanza-aprendizaje, destacar las principales características lingüísticas de los comentarios de TripAdvisor, así como ofrecer propuestas didácticas para su implementación.

El turismo es un fenómeno económico y social que hoy en día constituye uno de los sectores económicos con mayor rapidez de crecimiento a nivel mundial, pues durante décadas ha sufrido un crecimiento continuo y una gran diversificación, según la Organización Mundial del Turismo. En cuanto al español del turismo, se trata de un 
campo en plena expansión con una demanda que aumenta progresivamente y se enmarca en la enseñanza del español con fines profesionales (Efp).

El turismo es una disciplina técnico-científica estrechamente ligada con otras disciplinas, este hecho lo dota de un carácter interdisciplinar y multidisciplinar. Calvi (2006: 16) distingue en el ámbito turístico una gran diversidad de sectores y subsectores: la hostelería, los transportes y los seguros, el marketing, los encuentros y las reuniones profesionales, y la producción editorial. Este hecho se refleja en la lengua del turismo, tal y como lo transmite Balboni (1989:56), que la define como «un conjunto de micro lenguas interrelacionadas, que son utilizadas en los diferentes contextos por los que se mueve el operador turístico (hostelería, restauración, oficinas de turismo, etc.)». En cuanto al lenguaje, Calvi (2006: 19) lo caracteriza por «una gran variedad temática y una formación de léxico específico bastante limitada» y añade que para considerar este un lenguaje con fines específicos es necesario renunciar a una concepción léxica en aras de un enfoque discursivo.

Por lo tanto, el español del turismo se incluye en las lenguas de especialidad que definen Cabré y Gómez de Enterría (2006: 12) como «subconjuntos de recursos específicos, lingüísticos y no lingüísticos, discursivos y gramaticales que se utilizan en situaciones consideradas especializadas por sus condiciones comunicativas». Asimismo, siguiendo a Gómez de Enterría (2009: 51) los textos especializados se pueden clasificar en tres categorías. En un primer nivel se encuentran los discursos de especialización científica (el emisor y el receptor poseen una base científica), en un segundo nivel están los discursos semi-divulgativos (el emisor es especialista, pero el receptor no lo es) y, por último, los discursos divulgativos (el emisor no es un investigador y el receptor es un interesado en el tema). El caso que aquí nos ocupa, las críticas escritas por usuarios de TripAdvisor, se puede incluir en este último tipo de discurso.

\section{Los cibergéneros}

La comunicación mediada por ordenador (CMO) o también conocida en inglés como Computer Mediated Communication (CMC) se puede definir como «el conjunto de modalidades de interacción que surge de la aplicación de las nuevas tecnologías a la comunicación pública e interpersonal» (Pano y Moya, 2016: 2). Por su parte, Herring y Androutsopulos (2015: 127) utilizan el término discurso mediado por ordenador (DMO) para referirse a este tipo de comunicación y la definen como «la comunicación producida cuando los seres humanos interactúan entre sí mediante la transmisión de mensajes a través de ordenadores en red o móviles, donde los "ordenadores" se definen ampliamente para incluir cualquier dispositivo de comunicación digital».

Hoy en día conviven diferentes términos para referirse a este tipo de comunicación, depende del autor y, en ocasiones, de su variedad lingüística. Como ejemplo se hallan las denominaciones: comunicación mediada por computador/a, discurso digital, discurso mediado por computador/a, lenguaje digital, lenguaje en la red, comunicación electrónica, discurso electrónico, lenguaje electrónico o lenguaje de Internet. En este trabajo nos decantamos por la comunicación mediada por ordenador (CMO) por ser la mayoritaria.

Este tipo de comunicación originariamente era exclusiva de sectores militares, gubernamentales, universidades y negocios, pero a partir de mediados y finales de la 
década de los 90 del siglo pasado se popularizó, durante la «época dorada» de la CMO (Herring, 2010: 1). Actualmente está relacionada, según Pano y Moya (2016: 6), con características como la interactividad, la hipertextualidad, la multimodalidad, así como la participación de los usuarios en la generación de los contenidos. Esta tipología incluye intercambios de texto a través del correo electrónico, la mensajería instantánea, los chats en tiempo real, los foros de discusión asincrónica, las páginas web, las redes sociales, los mensajes de texto en teléfonos móviles, los blogs, las wikis, los canales de comunicación gráficos, los de vídeo o los de audio... Así, este tipo de comunicación se puede dividir en sincrónica, si se produce en tiempo real (por ejemplo, los chats, los mensajes instantáneos...), y asincrónica, cuando no es simultánea (los correos electrónicos, los foros de debate...).

Los cibergéneros o géneros digitales son una nueva clase de género que ha aparecido por la gran evolución de la Red. El cibergénero está caracterizado por el contenido, la forma y la funcionalidad, es decir, las capacidades que puede ofrecer (Sheperd y Watters, 1998). En cuanto a su clasificación, los cibergéneros se pueden diferenciar en existentes en otros medios (como puede ser el caso de un periódico en papel o un periódico en línea) o nuevos, los surgidos en el propio medio digital:

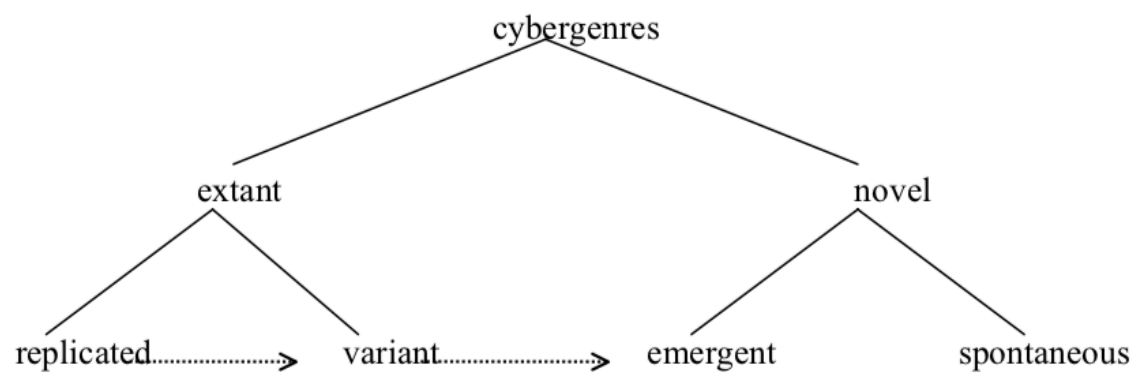

Fig. 1: Esquema de la clasificación de los cibergéneros (Shepherd y Watters, 2004)

TripAdvisor, la plataforma que nos ocupa, forma parte de los géneros nuevos, pues ha surgido con la aparición de las nuevas tecnologías y pertenece a la denominada comunicación asincrónica. En lo referente al lenguaje que se utiliza en este tipo de comunicación electrónica, son muchos los estudiosos que indican que se trata de un discurso híbrido (Briz, 2014; Kerbrat-Orecchioni, 2007; Androutsopoulos, 2006; Calvo Pérez, 2018), «escrito en relación con el canal y oral en cuanto a su realización» (Briz, 2014: 77), además de observarse rasgos de coloquialidad, especialmente en interactuantes jóvenes. Los rasgos a los que Briz (2014) se refiere son: acortamientos de palabras y frases, pérdida de sonidos, fenómenos de fonética sintáctica, alteración de algunos signos ortográficos, falta de acentuación, sintaxis concatenada, presencia de muchas partículas discursivas, saludos y despedidas orales coloquiales, voces jergales, nuevas palabras o acepciones, dialectalismos, vulgarismos, cambios de código, lenguaje no verbal a través de emoticones, risas, intensificación o lenguaje directo.

\subsection{El caso de TripAdvisor}

La llegada de la plataforma TripAdvisor ha propiciado la modificación de la guía de viaje tradicional, convirtiéndose en lo que Calvi (2016) denomina la «guía colaborativa» 
con la participación, la construcción y la modificación de conocimiento por parte de la comunidad de viajeros con un carácter subjetivo.

Son muchas las autoras que han llevado a cabo estudios lingüísticos sobre TripAdvisor, especialmente en lengua inglesa como Vásquez (2011, 2012), Zhang y Vásquez (2014), Suau Jiménez (2017) o Cenni y Goethals (2017), en el caso español podemos citar a Hernández y Mariottini (2016) o Fiorello (2014).

La plataforma TripAdvisor se define como un portal internacional dedicado al turismo. González (2012: 41) afirma que «el concepto participativo de esta red permite a los usuarios insertar críticas de servicios, locales, lugares, compañías, etc. Los miembros de la comunidad de viajeros pueden ver, en el perfil de sus contactos, los lugares que estos han visitado y las críticas que han escrito». Esta autora (2012: 42) indica que «la variedad de tipos de usuarios dota de gran heterogeneidad estilística este género».

\section{Metodología}

Se ha recopilado un corpus abierto, y ampliable en el futuro, de 200 comentarios de hispanohablantes procedentes de la plataforma de turismo más utilizada, TripAdvisor. Se trata de las opiniones de los clientes de tres conocidos establecimientos hoteleros situados en la ciudad de Santander, todos ellos de cuatro estrellas. Estos comentarios corresponden al periodo comprendido entre el 4 de abril de 2018 y el 30 de diciembre de 2018.

En esta plataforma, las opiniones se clasifican en «excelente», «muy buena», «normal», «mala» y «pésima». En este corpus se han recogido 123 clasificadas como malas y 77 como pésimas, centrándonos de esta forma en la queja. Se trata de un total de 22.333 palabras.

Con este corpus se han establecido las características pragmalingüísticas de estas intervenciones para poder elaborar las propuestas didácticas posteriores y llevarlas al aula.

\section{Resultados}

Tras analizar este corpus se puede afirmar que:

a. Las temáticas sobre las que giran los comentarios, las de los aspectos positivos y las de los negativos, en muchos casos, son las mismas, aunque como es lógico la valoración negativa es más abundante. 


\begin{tabular}{|c|c|}
\hline $\begin{array}{c}\text { Temáticas en las que predominan las } \\
\text { valoraciones positivas }\end{array}$ & $\begin{array}{c}\text { Temáticas en las que predominan las } \\
\text { valoraciones negativas }\end{array}$ \\
\hline $\begin{array}{c}\text { Tamaño de la habitación } \\
\text { Instalaciones } \\
\text { Personal } \\
\text { Situación } \\
\text { Colchón } \\
\text { Televisiones } \\
\text { Restaurante } \\
\text { Cafetería } \\
\text { Limpieza } \\
\text { Ubicación }\end{array}$ & $\begin{array}{l}\text { Mobiliario, calefacción, insonorización, } \\
\text { colchón, almohada, limpieza, restaurante, olor, } \\
\text { decoración, comida, aire acondicionado, } \\
\text { personal, jacuzzi, salones, armario, fachada, } \\
\text { pasillos, persianas, wifi, puertas, baño, } \\
\text { ubicación, precio, ventanas, cortinas, luz, } \\
\text { aparcamiento, televisión, ascensor, acceso, } \\
\text { tamaño. }\end{array}$ \\
\hline
\end{tabular}

Fig. 2: Temáticas en las que predominan las valoraciones positivas y negativas

b. Dentro de cualquier comentario negativo hay una alusión a un aspecto positivo. Este hecho sucede de igual forma en las quejas en lengua inglesa, como da prueba de ello Vásquez (2011).

(1) Hotel muy bien ubicado en la playa del Sardinero con fabulosas vistas. La habitación da la impresión de estar de regreso en los años setentas. Ventanales extremadamente sucios. El baño aunque al parecer renovado, hecho con muy mal gusto, materiales baratos y rotos, y un olor insoportable. Los servicios del restaurante no los hemos utilizado. Yo no lo recomendaría.

(2) La habitación tipo «suite» es enorme, de una calidad grande, aunque con algunos años, pero en buen estado de conservación. Lo que es deficiente en un hotel de estas características es que sólo tengas una almohada, baja y fina como un papel. Además, se hace difícil dormir con un ruido de motor de aire acondicionado o lo que quiera que sea hasta las 12 de la noche o más tarde. Lo dicho, es una pena estos detalles porque es un hotel con unas grandes instalaciones.

c. En las valoraciones coexisten descripción y narrativización de la propia experiencia de los usuarios.

(3) Habitación muy amplia pero con mobiliario viejo y muy fría. El sistema de calefacción hace bastante ruido y no funciona [...] La insonorización tampoco es buena y el ruido de los coches es más que apreciable. El colchón más que amortizado.

(4) Hotel de cinco estrellas, la habitación es tipo suite, bastante grande, pero muy deteriorada, puertas golpeadas, la madera saltada, sofás y sillas con manchas, las puertas correderas del armario se atascaban, moho en el baño. El buffet del hotel muy escaso y de poca calidad. El Wifi en la habitación no funcionaba.

(5) Francamente me decepcionó en general. En cuanto a la decoración solo voy a decír que es para echar a correr. El primer día que llegué comuniqué en recepción que la ventana de la habitación no cerraba correctamente. Me comunicaron que avisarian para arreglarla y el día que me marché la ventana seguía sin cerrar. En cuanto a la comida y el servicio de habitaciones e de decir que deja mucho que desear. Tras hacer el pedido me traen un plato combinado totalmente diferente al que yo había pedido (También e de decir que para ser un 4 estrellas el plato combinado era digno de un fast food de $5^{\mathrm{a}}$ categoria, patatas fritas congeladas y «hamburguesa» de calamar a lo que yo llamaría masa con sabor a algo menos a calamar por supuesto precocinado congelado de baja calidad y una ensalada con dos rodajas de tomate y cebolla roja) 12 Euros. Llamo para pedir explicación y me dicen que tendré la carta antigua pero que aún así les dijera lo que quería para cenar. Mi respuesta fue que no me atrevía a pedir nada puesto que tenia la carta antigua. Insistió la persona que me cogio el teléfono en que querría para cenar mientras hablaba con el cocinero en si me podía cocinar esto o lo otro... al final me dijo que me 
subiría una carta nueva. Así lo hizo la carta era similar excepto el plato que yo había pedido. Pienso otra opcion en mi caso son pocas por intolerancias me decido por una hamburguesa de pollo crujiente ¿como se imaginan una hamburguesa? Su pan de hamburguesa redondo, pollo tomate lechuga verdad?? Pues miren la foto que voy a colgar. Pan recalentado del día anterior con pollo crujiente gracias a su rebozado de un dedo de grosor de precocinados congelados de mala calidad. Pedí también postre arroz con leche y tampoco tenian decidí no pedir mas. En resumen calidad pésima en la cocina y en servicio de habitaciones. Adjunto fotos también de como me encontré el sofá nada más llegar a la habitación con alguna mancha sospechosa. Se me calleron también unas migas del rebozado del pollo debajo de la mesa y me estuvieron acompañando el resto de la semana. Llegamos al hotel a media tarde para una estancia de tres noches y nos dirigimos para realizar el registro. Lamentablemente para nosotros, nos acercamos al mostrador y la chica que estaba atendiendo en ese momento, de nombre Susana, no nos dirigió ni la mirada, ni un hola, ni una sonrisa... nos pidió los DNIs y tras entregarlos para que nos dieran habitación, nos dimos cuenta que mientras masticaba chicle, mantenía una conversación de temas personales con otro compañero de recepción. Me pareció una falta de respeto hacia los clientes que estábamos allí presentes, pues además tenía un tono bastante borde y parecía que la molestara que estuviéramos allí. Nos despachó rápidamente por lo que decidimos subir a la habitación a descansar un rato y tratar de bajar más tarde para pedir algunas informaciones y recomendaciones de la ciudad. Pasadas unas horas, bajamos de nuevo a recepción y la solicitamos (coincidió que estaba ella otra vez atendiendo) un mapa, esperando que nos diera algunas indicaciones, nos dejó el mapa encima del mostrador y se acabó, ni una explicación de donde estábamos, nada!! Nos quedamos realmente sorprendidos, por lo que decidimos pasar y acercarnos a la oficina de turismo que hay justo al lado para preguntar las dudas normales de cualquier turista ${ }^{1}$.

d. Como consecuencia de lo anterior, los tiempos verbales que predominan son los pretéritos (perfecto, indefinido y pluscuamperfecto) y el presente, los tiempos verbales más utilizados en los textos narrativos y descriptivos.

e. Los actos de habla que predominan son los directivos. Hay recomendaciones para otros futuros clientes, peticiones para críticos o responsables de los hoteles.

(6) Si eres aprensivo a este tipo de exposiciones no bajes a tomar café.

(7) A los señores que conceden las estrellas, por favor, vuelvan por aquí y revísenlas.

También están presentes los actos compromisorios:

(8) No volveré a este hotel...

(9) Sin duda no volveremos a este hotel

f. En cuanto al estilo, hay una gran presencia de lenguaje informal y coloquialismos: tener pinta de, para más inri, repelús, dar cosa, vivir un calvario, currar, señor borde...

g. Se han detectado muestras de ironía.

(10) Pero nos llamó la atención una gotera que caía encima de uno de los cruasanes... (jajajaj muy apetecible...) (Este usuario ironiza con el hecho de que los cruasanes tendrán un sabor más delicioso con el agua que cae de la gotera)

(11) No sé a quién se le ocurrió la maravillosísima idea de plantar una cabeza de elefante, otra de bisonte y algunas calaveras de diversos animales por tooooda la estancia... sin contar el estampado de cebra y demás «pieles»... (Se utiliza el morfema derivativo -ísima con valor intensificador para ironizar sobre la idea del decorador del hotel)

(12) Si quieres pasar una noche y salir corriendo, no es mala opción (Se muestra la ironía con la oración condicional que indica el deseo de ir una noche a un hotel y querer salir corriendo, cuando no es lo más apetecible para un huésped)

\footnotetext{
${ }^{1}$ Se ha mantenido la ortografía original de todos los ejemplos.
} 


\section{Posibilidades didácticas}

Además del uso de TripAdvisor como herramienta para trabajar en el aula las características anteriores, también se aplican para desarrollar la competencia discursiva, aspecto clave para los aprendientes de español. La definimos, siguiendo a Fernández (2010: 351), como «la capacidad de interaccionar lingüísticamente en el marco de un acto de comunicación, captando o produciendo textos con sentido, que se perciban como un todo coherente y adecuado a la situación y al tema». Esta autora afirma que esto conlleva:

- Que los textos respondan a un tema dado y desarrollen una o más funciones.

- Que los textos tengan coherencia interna lógica semántica: continuidad, unidad y coherencia temática, organización y estructura.

- Que los textos tengan en cuenta la situación de comunicación: interlocutores (posición social y situación relativa), lugar, función e intención, tono y género.

- Que los textos tengan cohesión externa: deícticos y anafóricos, conectores e índices, tiempo y aspecto, y puntuación.

Las ventajas del uso de este material en el aula de Efp son las siguientes:

- Se trata de un material real

- Los estudiantes poseen conocimientos previos sobre el funcionamiento de la plataforma en su lengua-cultura de origen, así que pueden anticiparse

- Se trata de un material motivador

- Se pueden trabajar diferentes destrezas

- Se pueden trabajar diferentes competencias, incluida la competencia digital y, especialmente, la competencia discursiva

- Favorece el desarrollo de habilidades y actitudes de «aprender a aprender»

- Es un material válido para distintos niveles

- Favorece las estrategias de mediación

Basándonos en este marco se han elaborado seis propuestas didácticas diferentes, que son las que se exponen a continuación.

Propuesta 1 (A partir de nivel B2): En la primera fase de esta propuesta se propone hacer una búsqueda de las quejas de un determinado hotel para posteriormente hacer una lista de los temas de esas quejas y terminar con una tarea de expresión escrita. En la segunda fase esos textos se reparten entre los estudiantes y deben analizar estos textos con una propuesta de preguntas y cuestiones. 
Propuesta 3 (A partir de nivel A2): En esta actividad se propone la utilización de las opiniones de TripAdvisor como input para trabajar contenidos gramaticales, en este caso, tiempos verbales del pasado, el pretérito indefinido y el pretérito imperfecto.

\section{Subraya las formas verbales que encuentres en pretérito indefinido y en pretérito imperfecto en estos comentarios de Tripadvisor:}
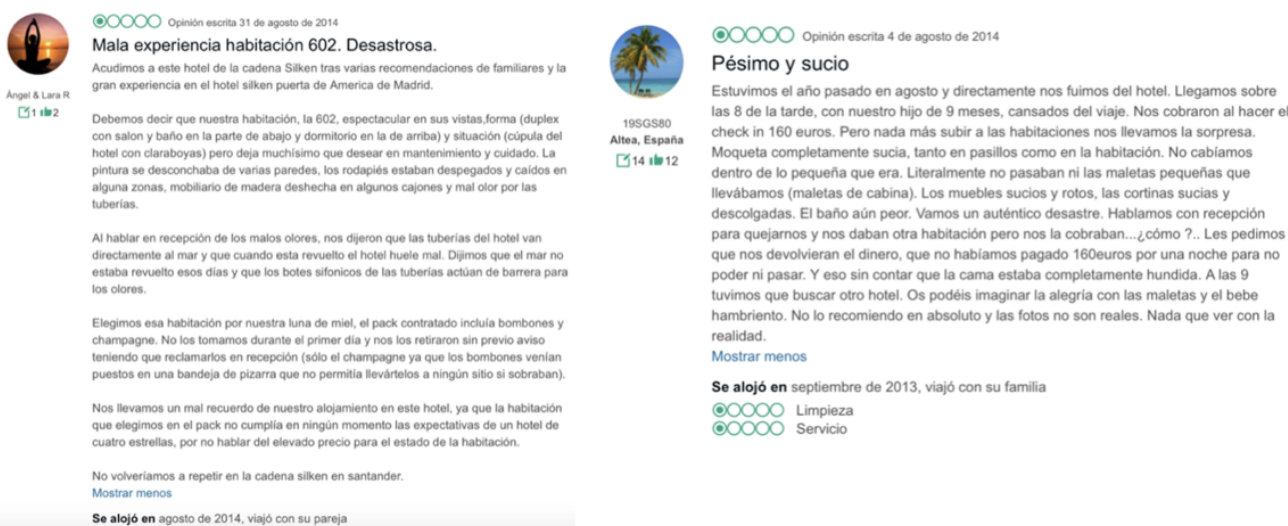

\section{¿Cuándo se utiliza cada tiempo verbal?}

Fig. 6: Opiniones de TripAdvisor para utilizar como input verbal

Propuesta 4 (Niveles A1 y A2): Como ya se ha hecho referencia anteriormente, TripAdvisor es un material que se puede utilizar en un amplio espectro de niveles. Esta propuesta está destinada a los más niveles más bajos, A1 y A2. La categorías en las que se clasifican las opiniones en esta plataforma son Excelente, Muy bueno, Normal, Malo y Pésimo, así que se propone su clasificación en comentarios positivos y negativos y justificarla.

\section{En esta plataforma los comentarios se clasifican en:}

\section{Excelente}

$$
\text { Muy bueno }
$$

Clasifica estos comentarios en comentarios positivos y negativos y explica la razón.

Tanquilidad y descanso

Muy recomendable por su ubicación frente al mar,paseo marítimo,tranquilidad,autobús para ir al centro cercano,se puede aparcar en la zona gratis también hay una zona cercana con varios restaurantes $\mathrm{y}$ bares.

Necesita reforma

Nos quedamos en la suite, más en concreto en la cúpula, debiese ser la mejor habitación del hotel y nada más lejos. Cada vez que abrías el grifo empezaba a oler a cañerias, muy desagradable. No funcionaba el secador tampoco. Se nos abrieron las ventanas solas en medio de la noche. Además la habitación está pintada a parchazos, como si hubiesen hecho obra y lo hubiesen dejado a medias. le falta una buena reforma. Lo mejor las vistas....inmejorables...
"Recomendable"

El hotel está muy bien ubicado ,El mobiliario de las habitaciones es clasico pero las camas son muy comodas en general la habitación muy bien y si te dan un piso alto tienes muy buenas vistas, nosotros tuvimos un pequeño problema con la habitación y nos cambiaron a otra mejor „La gente de recepción muy simpatica y amable . Lo negativo que para ser un hotel de 4 estrellas el mobiliario de recepción y las zonas comunes son muy viejas..

La ubicación es una maravilla

La ubicación sin duda es una maravilla. Si tienen habitación con vistas al mar, podrán ver en primera linea amanecer y atardecer que es sin duda lo mejor de la estancia. Las camas muy cómodas.

El desayuno Buffet bueno y de calidad, menos el café, la máquina un poco anticuada.

Los ascensores hacían un ruido al subir que no daba mucha seguridad.

Por otro lado el personal (no todos) tendria que refrescar

Fig. 7: Propuesta de clasificación de los comentarios para niveles A1-A2 
Propuesta 5 (A partir de nivel B1): Esta actividad se utiliza para trabajar la expresión e interacción escritas. En un primer paso los estudiantes deben leer el comentario de TripAdvisor sobre el establecimiento y con una serie de consejos deben escribir una respuesta. Se recomienda proporcionar a los estudiantes algunos ejemplos de respuestas reales.

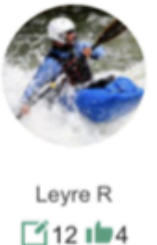

OOOOO Opinión escrita 10 de octubre de 2015

\section{Oia a la gente de la habitación de al lado respirar.}

Cuando llegamos al hotel parecía un hotel normal, algo viejo y bastante escaso para ser un 4 estrellas, pero lo realmente malo de mi experiencia en este hotel es que a un lado de la habitación habia una puerta con un pestillo que comunicaba mi habitación con la de al lado y por lo que se oía todo. Oía a la gente de la lado hablar, si ponian la televisión o si hacian pis. Era como tener a unos desconocidos en mi habitación, y cuando pedimos algún cambio o una solución nos dijeron que eso era imposible, y cuando dijimos que entonces no queriamos alojarnos en el hotel nos dijeron que de todos modos nos iban a cobrar el precio integro de la habitación.

Mostrar menos

Se alojó en octubre de 2015, viajó con su pareja

○0000 Habitaciones

○0000 Servicio

Pregunta a Leyre R sobre Santemar Hotel

Ib 4 Gracias, Leyre $\mathbf{R}$

Fig. 8. Opinión negativa sobre el establecimiento al que los estudiantes deben dar respuesta

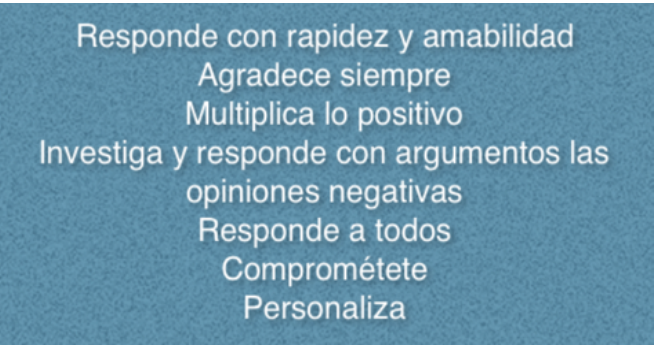

Fig. 9. Consejos para escribir la respuesta corporativa por parte del hotel

Propuesta 6 (A partir de nivel B1): En esta se propone el trabajo del significado del léxico por inducción. Los estudiantes deben leer el comentario y contestar a las preguntas. 
Lee este comentario y contesta a las preguntas:

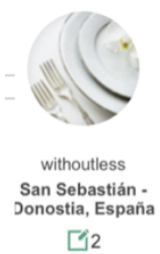

O०००० Opinión escrita 21 de noviembre de 2016

he estado en pensiones por menos de la mitad de precio más agusto $\mathrm{y}$ he comido mejor $=($

El hotel es amplio y tiene aspecto señorial, sobre todo para quien le agrade la caza y la tauromaquia. La decoración está dedicada a la matanza de animales. En el piso inferior donde se sitúa el bar y el restaurante del hotel destaca una gran cabeza de elefante como fondo exótico del sofá que tienen para descansar y al rededor toda una colección de ciervos y cabezas de animales salvajes colgadas. A mi, personalmente todo esto me parece tétrico de mal gusto y poco acogedor. En el comedor una gran colección de fotos de los dueños con diferentes toreros y sus familias, y como no, animales marinos colgados en las paredes.. jara y sedal... Estuvimos cenando alli y tenían una gran gotera que inundaba gran parte del comedor, pero como es amplio, o nos molestó.Mencionar, que la comida no era nada del otro jueves y que la sacaban calentada del microondas, con lo que se enfriaba en seguida si no te dabas prisa en comerla. El pescado estaba pasado y lo sirvieron templado las habas para cenar, también. El pasillo del del segundo piso está pintado de un color morado- violeta, que da la impresión de estar en un colegio de primaria, y ya alli hay un olor bastante desagradable, como de sitio viejo. El olor es peor cunado llegas a las habitaciones que parecen haber estado cerradas durante siglos. Muy amplias y espaciosas, eso, si. Bueno, tan espaciosas, que la nuestra que era doble, en el hall tenía una puerta abierta. La habitación misteriosa.. abrimos esta puerta para saber qué era lo que había dentro y nos encontramos con que era la habitación de otros inquilinos, que estaban ya acostados, y a los despertamos. Entendemos que haya habitaciones que se comuniquen, pero que no cerraran la puerta antes de entregarnos la llave, es incomprensible. Las sábanas, aunque limpias, olian fatal, y el baño, aunque limpio también , estaba lleno de cal, y daba bastante repelús. La puerta del balcón era corredera, pero del año de la polca y costaba mucho abrirla y cerrarla, se notaba que no éramos los primeros en tener este problema porque las cortinas estaban llenas de manchas de lluvia y barro de dejar la puerta abierta.

El desayuno de la mañana siguiente en bufet estaba bien compuesto y habia de todo. Pero nos llamó la atención una gotera que caía encima de uno de los crossan-es... (jajajaj muy apetecible...). Ese dia nos dimos cuenta de que habla goteras en gran parte del hotel. ETservicio del hotel en cuanto a los camareros del buffet y de la cena del restaurante estuvo bien, nos atendieron con amabilidad. En recepción un trato correcto, pero sin más. Para ser un hotel de 4 estrellas deja mucho que desear. Le vendría bien una renovación.

\section{1. ¿Qué significa ser del año de la polca? \\ A) Un momento en el que se baila mucho ese baile \\ B) Antiguo \\ C) De la República Checa}

2. En la oración subrayada se entiende que:

A) Ese tipo de bollería está más sabroso cuando le caen goteras

B) Ese producto tiene mal sabor con goteras:

Fig. 10: Propuesta para trabajar el léxico por inducción

\section{Conclusiones}

Como conclusiones, se puede señalar que este nuevo cibergénero es un material adecuado y necesario para el aula de lenguas extranjeras, en especial para el aula de español del turismo debido a su flexibilidad como material real para desarrollar diferentes competencias, trabajar todas las destrezas, ayudar a desarrollar habilidades de «aprender a aprender», ser válido para una diversidad de niveles y ser un material motivador para los aprendientes de español. Por lo tanto, como docentes se debe implementarlo en el aula de español del turismo.

Además, los comentarios negativos de TripAdvisor, es decir, las críticas o las quejas, se caracterizan por poseer muestras de ironía, lenguaje informal y coloquialismos en virtud de su carácter escrito-oralizado. Además, disponen de funciones de recomendación y petición, y al tratarse de descripciones y narrativizaciones los tiempos verbales predominantes son los pretéritos y el presente. Asimismo, se han encontrado alusiones de aspectos positivos en las críticas negativas. 


\section{Bibliografía}

BALBONI, Paolo. 1989. «La microlingua del turismo come fascio di microlingue» en Paolo Balboni (ed.): Microlingue e letteratura nella superiore. Brescia: La Scuola, 5661.

BRIZ, Antonio. 2014. «Hablar electrónicamente por escrito». CHIMERA. Romance Corpora and Linguistic Studies, 1, 77-89.

CABrÉ, M. ${ }^{\text {a }}$ Teresa y Josefa GÓMEZ DE ENTERRÍA. 2006. Lenguajes de especialidad y enseñanza de lenguas. La simulación global. Madrid: Gredos.

CALVI, M. ${ }^{\text {a } V i t t o r i a . ~ 2016 . ~ « G u i ́ a ~ d e ~ v i a j e ~ y ~ t u r i s m o ~ 2.0: ~ L o s ~ b o r r o s o s ~ c o n f i n e s ~ d e ~ u n ~}$ género». Ibérica, 31, 15-38.

CALVI, M. ${ }^{\text {a }}$ Vittoria. 2006. Lengua y comunicación en el español del turismo. Madrid: Arco/Libros SL.

FERNÁNDEZ, Sonsoles. 2010. «La competencia discursiva» en Monográficos Marcoele 11. Antología de los encuentros internacionales del español como lengua extranjera, Las Navas del Marqués, 351-383.

CENNI, Irene y Patrick Goethals. 2017. «Negative hotel reviews on TripAdvisor: A cross-linguistic analysis». Discourse, Context \& Media, 16, 22-30.

FiORELlo, Chiara. 2014. Il linguaggio spagnolo del turismo nel web 2.0. TripAdvisor: Un caso di studio. Università di Bologna, Corso di Studio in Lingua, societa' e comunicazione.

GÓMEZ DE ENTERRÍA, Josefa. 2009. El español lengua de especialidad: enseñanza y aprendizaje. Madrid: Arco/Libros SL.

GONZÁLEZ GARCíA, Virginia. 2012. «El discurso del turismo en Internet: hacia una caracterización de géneros» en Sanmartín, J. (ed.) Discurso turístico e internet. Madrid: Iberoamericana/Vervuert, 13-50.

Herring, Susan y Jannis ANDroutsopoulos. 2015. «Computer-Mediated Disourse 2.0» en Deborah Tannen, Heidi E. Hamilton y Deborah Schiffrin (eds.): The Handbook of Discourse Analysis, Second Edition, 127-151.

HERRING, Susan. 2010. «Computer-Mediated Conversation: Introduction and Overview».Language@Internet, 7, artículo 2.

MARIOTTINI, Laura y M. a Isabel HERNÁNDEZ TORIBIO. 2016. «TripAdvisor y actos de habla. Delimitaciones teóricas y propuestas metodológicas para el análisis de las estrategias de atenuación de los actos directivos». Pragmática Sociocultural 4 (2), 149181.

PANO, Ana y Patricio MoYA. 2016. «Una aproximación a los estudios sobre el discurso mediado por ordenador en lengua española». Revista de Estudios Filológicos Tonos Digital, 30, 1-30.

SHEPERD, Michael y Carolyn WATTERS. 1998. «The Evolution of Cybergenres». Proceedings of the Thirtieth-First Annual Hawaii International Conference on System Sciences, 97-103. 
SHEPERD, Michael y Carolyn WATTERS. 2004. «Identifying Web genre: Hitting a moving target». Proceedings of the WWW2004 Conference. Workshop on Measuring Web Search Effectiveness: The User Perspective. New York: ACM.

SUAU, Francisca. 2017. «Construcción discursiva de la subjetividad en lengua inglesa: cuando los viajeros se quejan a través de sus opiniones en TripAdvisor» en Círculo de Lingüística Aplicada a la Comunicación, 72, 79-94.

VÁsQuez, Camilla. 2011. «Complaints online: The case of TripAdvisor». Journal of Pragmatics 43, 1707-1717.

ZHANG, Yi y Camilla VÁSQUEZ. 2014. «Hotels’ responses to online reviews: Managing consumer dissatisfaction», Discourse, Context \& Media, 6, 54-64. 